\title{
The Bioaccessibility of Phenolics, Flavonoids, Carotenoids, and Capsaicinoid Compounds: A Comparative Study of Cooked Potato Cultivars Mixed with Roasted Pepper Varieties
}

\author{
Mansor Hamed ${ }^{1}$, David G. Holm ${ }^{1}$, Michael Bartolo ${ }^{2}$, Pinky Raigond ${ }^{3}$, , Vidyasagar Sathuvalli ${ }^{4}(\mathbb{D}$ \\ and Sastry S. Jayanty ${ }^{1, * \mathbb{D}}$ \\ 1 San Luis Valley Research Center, Department of Horticulture and Landscape Architecture, \\ Colorado State University, 0249 East County Road 9N Center, Fort Collins, CO 81125, USA; \\ Mansor.Hamed@rams.colostate.edu (M.H.); David.Holm@colostate.edu (D.G.H.) \\ 2 Arkansas Valley Research Center, Department of Horticulture and Landscape Architecture, \\ Colorado State University, 27901 County Rd 21, Rocky Ford, CO 81067, USA; Michael.Bartolo@ColoState.EDU \\ 3 Crop Physiology, Biochemistry \& Post-Harvest Technology Division, ICAR-Central Potato Research Institute, \\ Shimla 171001, India; jariapink@gmail.com \\ 4 Hermiston Agricultural Research \& Extension Center, Oregon State University, $2121 \mathrm{~S}$ 1st Street, \\ Hermiston, OR 97838, USA; Vidyasagar@oregonstate.edu \\ * Correspondence: sastry.jayanty@colostate.edu; Tel.: +1-719-754-3594; Fax: +1-719-754-2619
}

check for

updates

Citation: Hamed, M.; Holm, D.G.; Bartolo, M.; Raigond, P.; Sathuvalli, V.; Jayanty, S.S. The Bioaccessibility of Phenolics, Flavonoids, Carotenoids, and Capsaicinoid Compounds: A Comparative Study of Cooked Potato Cultivars Mixed with Roasted Pepper Varieties. Foods 2021, 10, 1849. https://doi.org/10.3390/ foods10081849

Academic Editors: José

Manuel Moreno-Rojas, Gema Pereira Caro and Raquel Rodríguez Solana

Received: 5 July 2021

Accepted: 30 July 2021

Published: 11 August 2021

Publisher's Note: MDPI stays neutral with regard to jurisdictional claims in published maps and institutional affiliations.

Copyright: (c) 2021 by the authors. Licensee MDPI, Basel, Switzerland. This article is an open access article distributed under the terms and conditions of the Creative Commons Attribution (CC BY) license (https:/ / creativecommons.org/licenses/by/ $4.0 /)$.

\begin{abstract}
An in vitro method was used to assess the bioaccessibility of phenolics, flavonoids, carotenoids, and capsaicinoid compounds in different cooked potatoes mixed with roasted peppers (Capsicum annuum), Joe Parker (JP, hot), and Sweet Delilah (SD, sweet). The present study identified differences in the bioaccessibility of bioactive compounds among the potato cultivars (Solanum tuberosum) Purple Majesty (PM; purple flesh), Yukon Gold (YG; yellow flesh), Rio Grande Russet (RG; white flesh) and a numbered selection (CO 97226-2R/R (R/R; red flesh)). The bioactive compounds and capsaicinoid compounds in potatoes and peppers were estimated before and after in vitro digestion. Before digestion, the total phenolic content of potato cultivars mixed with JP was in the following order: R/R > PM > YG > RG. The highest levels of carotenoids were $194.34 \mu \mathrm{g} / \mathrm{g}$ in YG and $42.92 \mu \mathrm{g} / \mathrm{g}$ in the RG cultivar when mixed with roasted JP. The results indicate that the amount of bioaccessible phenolics ranged from 485 to $252 \mu \mathrm{g} / \mathrm{g}$ in potato cultivars mixed with roasted JP. The bioaccessibility of flavonoids ranged from 185.1 to $59.25 \mu \mathrm{g} / \mathrm{g}$. The results indicate that the YG cultivar mixed with JP and SD showed the highest phenolic and carotenoid bioaccessibility. In contrast, the PM mixed with JP and SD contained the lowest phenolic and carotenoid bioaccessibility. Our results indicate that the highest flavonoid bioaccessibility occurred in R/R mixed with roasted JP and SD. The lowest flavonoids bioaccessibility occurred in PM and the RG. The maximum bioaccessible amount of capsaicin was observed in YG mixed with JP, while the minimum bioaccessibility was observed with PM.
\end{abstract}

Keywords: pepper; potato; bioaccessibility; bioactive compounds; capsaicin

\section{Introduction}

Crops such as potatoes (Solanum tuberosum L.) and peppers (Capsicum annuum L.) are among the most common food crops in human diets; they are members of the Solanaceae family [1,2]. These crops have been excellent sources of various phytochemical compounds, such as vitamins, phenolics, carotenoids, and capsaicinoid compounds [3-5]. Due to the abundance of bioactive compounds, these crops exhibit many nutritional and health benefits when consumed at appropriate levels [6,7], making these foods highly desirable choices for frequent consumption. The biological effects of bioactive compounds such as antioxidant activity, antimicrobial, and anticancer depend on the amount of those components consumed in the daily diet and their bioaccessibility [8]. These compounds vary widely in 
their chemical structures and biological functions; their bioaccessibility is not well understood [9]. The bioactive compound's concentration and stability during food processing depend on several factors: the type and cultivar, growing conditions, geographical location, postharvest handling, processing conditions, and cooking methods [10-12]. It is important to obtain information about their bioaccessibility from the foods matrix and the factors that influence their bioaccessibility [13]. The bioaccessibility of bioactive compounds describes that part of the compound released from the food matrix and becomes available for absorption [14,15]. The combination of various food ingredients and cooking methods may significantly influence the bioaccessibility of bioactive compounds. Several studies have reported that it is possible to estimate the bioaccessibility of bioactive compounds by evaluating the quantity transferred to the micelle fraction following a simulated in vitro digestion procedure [15]. Several methodologies may be used to assess bioactive compounds' bioaccessibility; among them, the most common is in vitro digestion [16]. The bioaccessibility of bioactive compounds depends on various factors, including their abundance within the food matrix, the heat of processing, and food additives such as dietary fat, oil, and certain enzymes $[10,15]$. Processing methods such as boiling, roasting, drying, and frying have been observed to enhance bioaccessibility significantly [15,17]. Cooking methods of food can influence bioactive compounds' bioaccessibility, mainly through change and the disruption of the cell wall structure, leading to the release of these compounds, which implies higher bioaccessibility $[17,18]$.

A few studies have reported the bioaccessibility of bioactive compounds in mixed diets, although only limited information is available. Potatoes and peppers are some of the most frequently consumed food sources globally, providing significantly greater amounts of bioaccessible bioactive compounds [19]. There is a significant variation of phytochemical compounds such as phenolics, flavonoids, anthocyanins, and carotenoids among potato cultivars $[18,20]$. These compounds exhibited significant antioxidant, antiglycemic, antiviral, anticarcinogenic, and anti-inflammatory activities and showed antiallergic and antimicrobial properties [21,22].

Potato and peppers are often consumed as part of an elaborate meal, including such ingredients such as salt, fiber, protein, and fat. Thus, it is possible that these ingredients influence the bioaccessibility of bioactive compounds. This study investigates the bioaccessibility of phenolics, flavonoids, carotenoids, and capsaicinoid compounds in cooked potato cultivars mixed with two roasted pepper varieties via in vitro digestion experiments.

\section{Materials and Methods}

\subsection{Chemicals}

Folin Ciocalteu Reagent (FCR), sodium carbonate, gallic acid, potassium chloride, sodium acetate, quercetin, lutein, and all digestive enzymes ( $\alpha$-amylase, pepsin, pancreatin, and porcine bile extract) were purchased from Sigma-Aldrich (Saint Louis, MO, USA). HPLC-grade acetonitrile butyl alcohol, methyl-t-ethyl ether (MtBE), and methanol reagents were obtained from Thermo Fisher Scientific Inc (Waltham, MA, USA).

\subsection{Pepper and Potato Cultivars}

Peppers in this study were sourced from Arkansas Valley Research Center, Rocky Ford CO (AVRC) in July 2016. Two different pepper varieties, Joe Parker (JP; hot) and Sweet Delilah (SD; sweet), were used in this study. Pepper fruits were transported to the San Luis Valley Research Center, Center CO (SLVRC), after harvest to complete the bioaccessibility experiments. Four different potato cultivars-Purple Majesty (PM; purple flesh), Yukon Gold (YG; yellow flesh), Rio Grande Russet (RG; white flesh), and a numbered line (CO $97226-2 R / R$ (R/R; red flesh)) - were used in this study. The potato cultivars were harvested at the end of the 2015 growing season at SLVRC. 


\subsection{Cooking Methods}

Five to six pepper pods of each variety were washed, dried, and cut into small pieces with peduncles removed, then placed on an oven tray, transferred to a preheated oven set at $150{ }^{\circ} \mathrm{C}$, and roasted for $20 \mathrm{~min}$ in a conventional oven. The oven had been preheated for uniform heat distribution. Once removed from the oven, all sample pieces were cooled, freeze-dried (LABCONCO, New York, NY, USA), ground, and stored at $-20{ }^{\circ} \mathrm{C}$ until further analysis. Five potato tubers from each cultivar were collected at random, and the tubers were pierced twice on each side with a fork and baked at $204{ }^{\circ} \mathrm{C}$ for one hour in a commercial oven. All potato samples were then cut into small pieces, freeze-dried, ground using a coffee grinder, and stored at $-20^{\circ} \mathrm{C}$ until further analysis.

\subsection{Extraction and Estimation of the Total Phenolics and Flavonoids}

Total phenolics and total flavonoids were extracted with pure methanol. To $15 \mathrm{~mL}$ of $100 \%$ methanol, $0.4375 \mathrm{~g}$ of potato freeze-dried powder and $0.0625 \mathrm{~g}$ of roasted pepper freeze-dried powder were added and homogenized for $5 \mathrm{~min}$. Supernatants of pepper and potato extract were filtered to evaluate total phenolics and total flavonoids. The total phenolic content was calculated according to the method declared by [20] with modifications. FCR solution was added to pepper and potato extract, and sodium carbonate was added to the 96 microplates. The total phenolic content of pepper and potato samples was calculated as gallic acid equivalents $(\mu \mathrm{g} / \mathrm{g})$. A colorimetric method was used to evaluate the total flavonoid content in pepper samples. Aluminum chloride was added to the pepper extract in 96 microplates. The total flavonoid content of pepper samples was expressed as quercetin equivalents $(\mu \mathrm{g} / \mathrm{g})$.

\subsection{Extraction and Estimation of Total Carotenoids}

Total sample carotenoids were extracted with water-saturated butanol. To $15 \mathrm{~mL}$ of water-saturated butanol, $0.4375 \mathrm{~g}$ of potato freeze-dried powder or $0.0625 \mathrm{~g}$ of freeze-dried powder of roasted peppers was added and homogenized for $5 \mathrm{~min}$. The mixture was covered with aluminum foil and allowed to stand in the fume hood for $60 \mathrm{~min}$ at room temperature. The absorbance of the mixture was measured at $450 \mathrm{~nm}$. Lutein was used as the standard, and total pepper carotenoids were quantified as $\mu \mathrm{g}$ of lutein equivalent per gram of dry weight materials using a 5-point calibration curve with an $R^{2}$ value of 0.996 .

$\begin{gathered}\text { Total Carotenoids } \\ (\mathrm{mg} / \mathrm{g})\end{gathered}=\frac{\left(\frac{\text { Sample Abs }-\mathrm{y} \text { intercept }}{\text { slope }}\right) \times \text { Orig Vol }(\mathrm{L}) \times \begin{array}{c}\text { Dilution } \\ \text { Factor }\end{array}}{\text { Sample Weight }(\mathrm{g})}$

where: Sample Abs = Sample Absorbance; Orig Vol = Original Volume for sample preparation, in liters; Slope $=$ Slope from standard curve.

\subsection{Extraction of Capsaicinoid Compounds}

Extraction and quantification of capsaicinoid compounds were performed as described by [12]. A total of $0.500 \mathrm{mg}$ of freeze-dried ground pepper was added to a $15 \mathrm{~mL}$ polypropylene tube. Ten milliliters of methanol was added to each sample and placed in an orbital shaker overnight at $25^{\circ} \mathrm{C}$. The supernatant was transferred to a fresh $15 \mathrm{~mL}$ tube. The sample was re-extracted with $10 \mathrm{~mL}$ more of methanol, and the resulting supernatants were combined. One milliliter of the methanolic extract was filtered through a $0.45 \mu \mathrm{m}$ filter cartridge (Advanced Microdevices, Ambala, India) and poured into a $1.8 \mathrm{~mL}$ sample glass vial for HPLC analysis.

\subsection{Analysis of Capsaicinoid Compounds}

Capsaicin and dihydrocapsaicin were quantified using a Waters (Milford, MA, USA) HPLC system equipped with a fluorescence detector and a Waters Nova-Pak C18 $4 \mu \mathrm{m}$, $4.6 \times 150 \mathrm{~mm}$ C18 column. Aqueous methanol A (10\% methanol) and B (100\% methanol) were used as eluent with a flow rate of $0.4 \mathrm{~mL} / \mathrm{min}$, and a gradient of 0 to $10 \mathrm{~min}, 80 \%$ A and $20 \%$ B. The fluorescence detector was set to an excitation wavelength of $280 \mathrm{~nm}$ 
and an emission wavelength of $338 \mathrm{~nm}$. Levels of capsaicin and dihydrocapsaicin were estimated using a calibration curve with a standard of capsaicin and dihydrocapsaicin with concentrations ranging from 0.1 to $10 \mu \mathrm{g} / \mathrm{mL} . \mathrm{R}^{2}$ values were obtained from the standard curve of capsaicin and dihydrocapsaicin with 0.995 and 0.997 , respectively.

\subsection{In Vitro Digestion}

The in vitro digestion protocol described by [23] was performed with modifications in triplicate. In a $50 \mathrm{~mL}$ polypropylene tube, $0.4375 \mathrm{~g}$ of potato cultivar or $0.0625 \mathrm{~g}$ of roasting peppers were mixed with $5 \mathrm{~mL}$ of distilled water and homogenized by vortex for $30 \mathrm{~s}$. For salivary digestion, samples were treated with $1 \mathrm{~mL} \alpha$-amylase solution with enzymatic activity $24.0-36.0 \mathrm{U} / \mathrm{mg}(70 \mathrm{mg} / \mathrm{mL}$ in phosphate buffer of $0.1 \mathrm{M} \mathrm{pH}=6.9)$ at $37^{\circ} \mathrm{C}$ for $10 \mathrm{~min}$. Sample $\mathrm{pH}$ was adjusted to $\mathrm{pH} 2$ with $0.1 \mathrm{M} \mathrm{HCl}$. Samples were then treated with $0.3 \mathrm{~mL}$ pepsin with enzymatic activity $\geq 3200 \mathrm{U} / \mathrm{mg}(300 \mathrm{mg} / \mathrm{mL} \mathrm{HCl}-\mathrm{KCl}, 0.2 \mathrm{M} \mathrm{pH}$ $1.5)$ in a $37^{\circ} \mathrm{C}$ water bath to complete the gastric digestion phase. Samples were treated with pancreatin with enzymatic activity as markers $(5 \mathrm{mg} / \mathrm{mL}$, phosphate buffer, $0.1 \mathrm{M}$, $\mathrm{pH} 7.5)$ and $3.3 \mathrm{~mL}$ porcine bile extract $(17.5 \mathrm{mg} / \mathrm{mL}$ phosphate buffer, $0.1 \mathrm{M}, \mathrm{pH} 7.5)$ in a $37^{\circ} \mathrm{C}$ water bath to complete the intestinal digestion phase. The resulting digestates were centrifuged at $5000 \times g$ for $20 \mathrm{~min}$. Supernatants were collect and stored at $-80^{\circ} \mathrm{C}$ until further analysis. The bioaccessibility of bioactive compounds in this study is expressed as the percentage of bioactive compounds transferred to the aqueous phase during the in vitro digestion process (amounts of total compounds in the aqueous phase/amount compounds in the sample $\times 100)$.

\section{Statistical Analysis}

All experiments were carried out in triplicate, and the data were subjected to analysis of variance (ANOVA); Tukey's test was performed to determine significance at $p<0.05$ between treatments. All statistical analyses were performed with $\mathrm{R}$ software version 3.4.3 for Windows.

\section{Results and Discussion}

\subsection{Total Phenolics and Bioaccessibility}

Vegetables and fruits are the primary sources of dietary polyphenolics, such as phenolic acids, hydroxycinnamic acid derivatives, and flavonoids. These compounds provide many nutritional and health benefits, including antioxidant, anti-inflammatory, and antimicrobial activities $[5,20,24]$. Thus, phenolic compounds are recognized as rich sources of dietary antioxidants [3]. However, their health benefits correlate with their bioaccessibility [25]. Phenolic compounds such as chlorogenic acid, neochlorogenic acid, cryptochlorogenic acid, caffeic acid, p-coumaric acid, and ferulic acid are present at high concentrations in colored flesh potato cultivars and quercetin, luteolin, and capsaicinoids in pepper varieties; however, the bioaccessibility of these compounds can be highly variable.

The levels of phenolics and bioaccessible phenolics in potato cultivars mixed with roasted peppers are shown in Figure 1. Red-fleshed potato selection R/R mixed with roasted JP had the maximum amount of phenolics $(2164 \mu \mathrm{g} / \mathrm{g})$ followed by PM $(1621 \mu \mathrm{g} / \mathrm{g}), \mathrm{YG}(644 \mu \mathrm{g} / \mathrm{g})$, and RG $(339 \mu \mathrm{g} / \mathrm{g})$. Similar levels of phenolics (2316 to $329 \mu \mathrm{g}$ GAE/g FD) in the same order were obtained when mixed with roasted SD (Table 1). Higher levels of total phenolics were found in red and purple-fleshed tubers than in white and yellow cultivars [20]. These differences in total phenolic content could be attributed to various factors, including the variety, flesh color, starch content, and maturity stages [26]. 


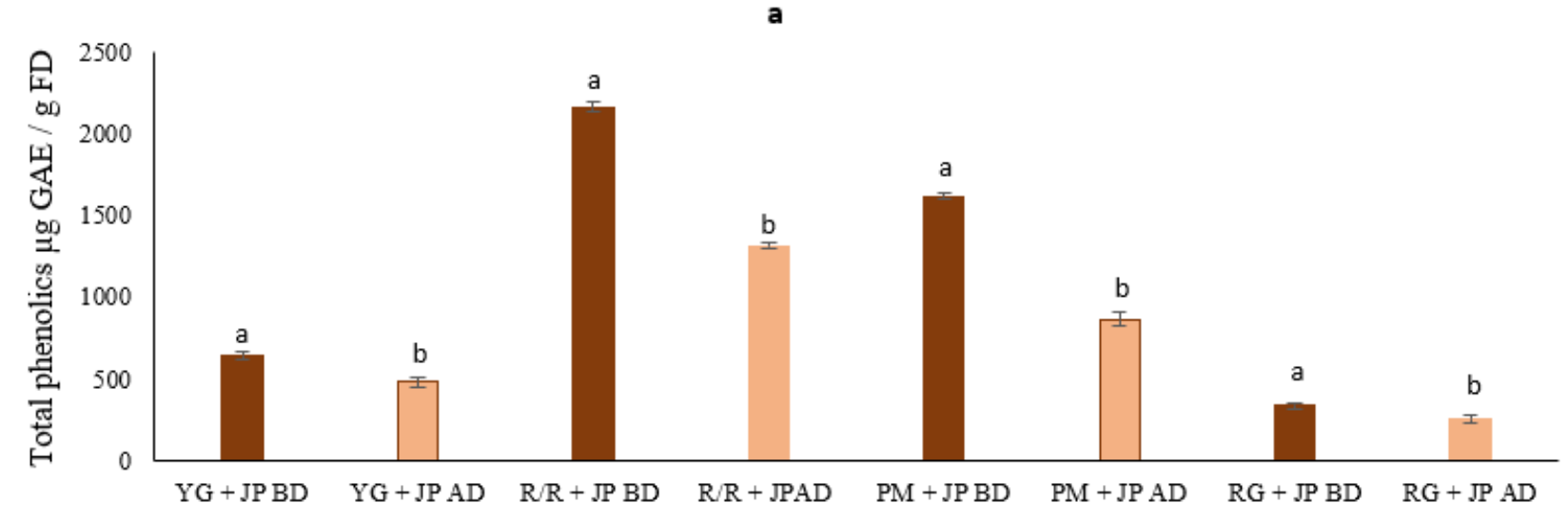

b

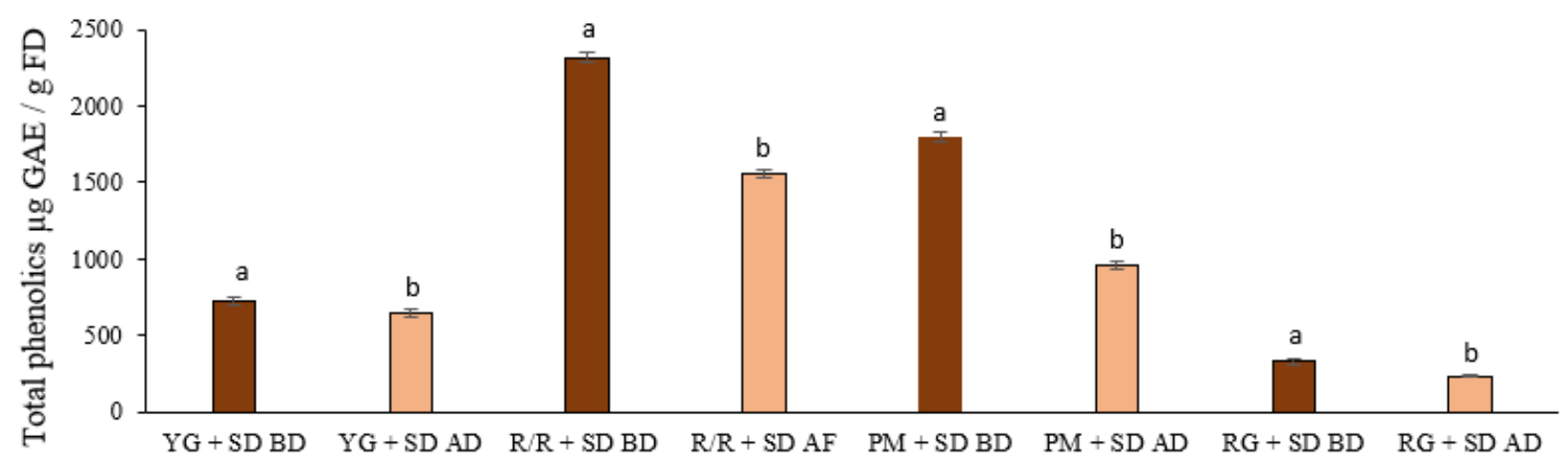

Figure 1. The levels of total phenolics and bioaccessibility of cooked potato varieties mixed with roasted JP (a) and with roasted SD (b). Data are the mean of three replicates with standard deviation and are expressed as per gram of freeze-dried weight. Significant differences are denoted by different letters, while the same or shared letters indicate that they are not significant to each other. BD and AD: before and after digestion.

After in vitro digestion, a significant reduction of total phenolics was observed in all samples, which agrees with an earlier report by Andre et al. (2015) [27]. The bioaccessible phenolic content was 1316, 869, 485, and $252 \mu \mathrm{g} / \mathrm{g}$ in R/R, PM, YG, and RG potatoes, respectively, when mixed with JP (Figure 1a, and Table 1). Our results indicate that $53-75 \%$ of phenolic compound content was released from potato cultivars mixed with JP; by contrast, the release was $53-88 \%$ in potatoes cultivars mixed with SD (Figure $1 \mathrm{~b}$ and Table 1). Our results show that the highest release of the phenolic compounds was observed in YG mixed with SD, whereas the lowest release of phenolic compounds was observed in PM mixed with JP. During gastric digestion, phenolic compounds were highly bioaccessible; $43.8-93.73 \%$ of phenolic compounds were released [7]. Several reports have established that the bioaccessibility of bioactive compounds is influenced by the composition of the digested food matrix and physicochemical properties, such as $\mathrm{pH}$, temperature, and texture of the matrix [13,27]. 


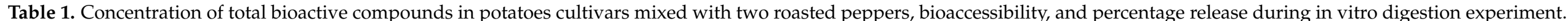

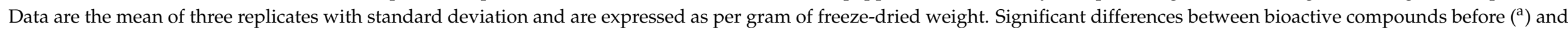
after digestion $\left({ }^{b}\right)$ are denoted by different letters, while the same or shared letters indicate that they are not significant.

\begin{tabular}{|c|c|c|c|c|c|c|c|c|c|}
\hline \multirow[b]{2}{*}{ Treatment 1} & \multicolumn{9}{|c|}{ Bioactive Compounds } \\
\hline & $\begin{array}{l}\text { Total Phenolic } \\
\mu \mathrm{g} \text { GAE/g FD }\end{array}$ & $\begin{array}{c}\text { Total Bioaccessible } \\
\text { Phenolics } \\
\mu \text { g GAE/g FD }\end{array}$ & $\%$ Release & $\begin{array}{c}\text { Total } \\
\text { Flavonoids } \mu \mathrm{g} \\
\text { QE/g FD }\end{array}$ & $\begin{array}{c}\text { Total Bioaccessible } \\
\text { Flavonoids } \mu \mathrm{g} \\
\text { QE/g FD }\end{array}$ & $\%$ Release & $\begin{array}{c}\text { Total } \\
\text { Carotenoids } \mu \mathrm{g} \\
\text { Lu/g FD }\end{array}$ & $\begin{array}{c}\text { Total Bioaccessible } \\
\text { Carotenoids } \mu \mathrm{g} \\
\text { Lu/g FD }\end{array}$ & $\%$ Release \\
\hline$Y G+J P$ & $644.3^{a} \pm 27$ & $485.7^{b} \pm 29$ & 75.3 & $75.3^{a} \pm 3.6$ & $59.25^{b} \pm 4.1$ & 78.6 & $194.3^{a} \pm 5.6$ & $151.7^{\mathrm{b}} \pm 5.6$ & 78 \\
\hline $\mathrm{R} / \mathrm{R}+\mathrm{JP}$ & $2164.3^{a} \pm 29$ & $1316.8^{b} \pm 20$ & 60.8 & $222.4^{\mathrm{a}} \pm 3.5$ & $185.18^{b} \pm 2.9$ & 83.2 & $133.2^{\mathrm{a}} \pm 5.5$ & $86.1^{\mathrm{b}} \pm 11.3$ & 64.6 \\
\hline $\mathrm{PM}+\mathrm{JP}$ & $1620.8^{a} \pm 19$ & $869.06^{b} \pm 42$ & 53.6 & $147.6^{\mathrm{a}} \pm 3.7$ & $96.7^{b} \pm 3.8$ & 65.5 & $81.6^{a} \pm 5.7$ & $53.4^{b} \pm 2.5$ & 65.4 \\
\hline \multirow[t]{2}{*}{$\mathrm{RG}+\mathrm{JP}$} & $338.7^{\mathrm{a}} \pm 20$ & $252.7^{b} \pm 22$ & 74.6 & $107.9^{\mathrm{a}} \pm 4.3$ & $74.07^{b} \pm 2.9$ & 68.6 & $42.9^{a} \pm 5.4$ & $30.4^{\mathrm{b}} \pm 1.8$ & 71 \\
\hline & \multicolumn{9}{|c|}{ Bioactive Compounds } \\
\hline Treatment 2 & $\begin{array}{l}\text { Total Phenolic } \\
\mu \mathrm{g} \text { GAE/g FD }\end{array}$ & $\begin{array}{c}\text { Total Bioaccessible } \\
\text { Phenolics } \mu \mathrm{g} \\
\text { GAE/g FD }\end{array}$ & $\%$ Release & $\begin{array}{c}\text { Total } \\
\text { Flavonoids } \mu \mathrm{g} \\
\text { QE/g FD }\end{array}$ & $\begin{array}{c}\text { Total Bioaccessible } \\
\text { Flavonoids } \mu \mathrm{g} \\
\text { QE/g FD }\end{array}$ & $\%$ Release & $\begin{array}{c}\text { Total } \\
\text { Carotenoids } \mu \mathrm{g} \\
\text { Lu/g FD }\end{array}$ & $\begin{array}{c}\text { Total Bioaccessible } \\
\text { Carotenoids } \mu \mathrm{g} \\
\text { Lu/g FD }\end{array}$ & $\%$ Release \\
\hline$Y G+S D$ & $723.6^{\mathrm{a}} \pm 19$ & $639.4^{b} \pm 26$ & 88.3 & $83.9^{a} \pm 3.6$ & $64.1^{b} \pm 3.5$ & 76.4 & $230^{\mathrm{a}} \pm 11.1$ & $184.5^{b} \pm 5.3$ & 80.1 \\
\hline $\mathrm{R} / \mathrm{R}+\mathrm{SD}$ & $2316.3^{a} \pm 32$ & $1556.3^{b} \pm 26$ & 67.1 & $277^{a} \pm 3.7$ & $231.1^{b} \pm 2.9$ & 83.4 & $165.5^{\mathrm{a}} \pm 9.6$ & $122.2^{b} \pm 5.6$ & 73.8 \\
\hline $\mathrm{PM}+\mathrm{SD}$ & $1794.3^{a} \pm 29$ & $960^{b} \pm 28$ & 53.4 & $167.1^{\mathrm{a}} \pm 5.2$ & $114.8^{b} \pm 3.3$ & 68.9 & $88.09^{a} \pm 9.1$ & $53.4^{b} \pm 5.7$ & 60.6 \\
\hline
\end{tabular}




\subsection{Total Flavonoids and Bioaccessibility}

Flavonoids are the most common group of polyphenolic compounds in plants. Flavonoids are natural polyhydroxylated compounds with a proven positive impact on human health. The impact of dietary flavonoids depends on their bioaccessibility. There is little published information on the bioaccessibility of flavonoid compounds following the in vitro digestion procedure.

The results in Figure 2 show the levels of flavonoids and bioaccessible flavonoids in different potato cultivars either mixed with roasted JP pepper (Figure 2a) or with roasted SD (Figure $2 b)$. A significant variation $(p \leq 0.05)$ was observed in the content of total flavanoids between different potato cultivars mixed with roasted JP (222.4 to $59.25 \mu \mathrm{g}$ $\mathrm{QE} / \mathrm{g}$ FD) and SD (277 to $83.9 \mu \mathrm{g}$ QE/g FD) before digestion (Table 1). Similarly, the bioaccessibility of flavonoid compounds ranged from 185 to $59 \mu \mathrm{g}$ QE/g FD and from 231 to $64 \mu \mathrm{g}$ QE/g FD for potato cultivars mixed with JP and SD, respectively. The total flavonoid content and bioaccessibility of flavonoid compounds among the potato cultivars we tested was in the order R/R > PM > RG > YG, irrespective of peppers in the study (Table 1 and Figure 2). Our results show that the release of flavonoid compounds ranged from 65 to $83 \%$ in potato cultivars mixed with JP, whereas this release ranged from 58 to $83 \%$ in potato cultivars mixed with SD. Previous studies have shown that purple and red cultivars had twice the flavonoid concentration of white cultivars [28]. Various studies suggested that variations in flavonoid levels are primarily the result of the diversity of genotypes, landraces, varieties, and the ripening stage of the fruits [29]. Several studies reported that flavonoid bioaccessibility was dependent on the digestible and non-digestible fibers in the tested food product [30]. Previous studies reported that thermal treatments during food processing increased bioactive compounds' bioaccessibility [31].

\subsection{Total Carotenoids and Bioaccessibility}

Carotenoids are a large class of bioactive compounds responsible for the attractive color of many fruits and vegetables. Due to the pro-vitamin A activity, carotenoids constitute a significant source of antioxidants associated with health benefits [32]. Carotenoid bioaccessibility depends on the degree of food processing and matrix composition [33].

Yellow flesh cultivars have generally shown a much higher average of total carotenoid content when compared to red and purple-fleshed potatoes [34]. Our studies show that carotenoid levels (194 to $43 \mu \mathrm{g} \mathrm{Lu} / \mathrm{g}$ FD) and carotenoid bioaccessibility (152 to $30 \mu \mathrm{g} \mathrm{Lu} / \mathrm{g}$ FD) varied in four potato cultivars when mixed with JP (3a). Higher levels of carotenoids were present in YG and R/R mixed with JP compared to PM and RG. Similarly, total carotenoid levels are between 230 and $49 \mu \mathrm{g} \mathrm{Lu} / \mathrm{g}$ FD, and the bioaccessibility of carotenoids ranged from 185 to $17 \mu \mathrm{g} \mathrm{Lu} / \mathrm{g}$ FD in potato cultivars when mixed with roasted SD (3b). There are no significant differences in the \% release of carotenoids between JP and SD except the cultivar effect (Figure 3 and Table 1). The differences in the release of flavonoids and carotenoids between JP and SD could be explained by several factors, such as the physical and chemical nature of the food matrix, cooking methods, solubility, and polarity of carotenoids, and interaction with other compounds during the digestion procedure. 

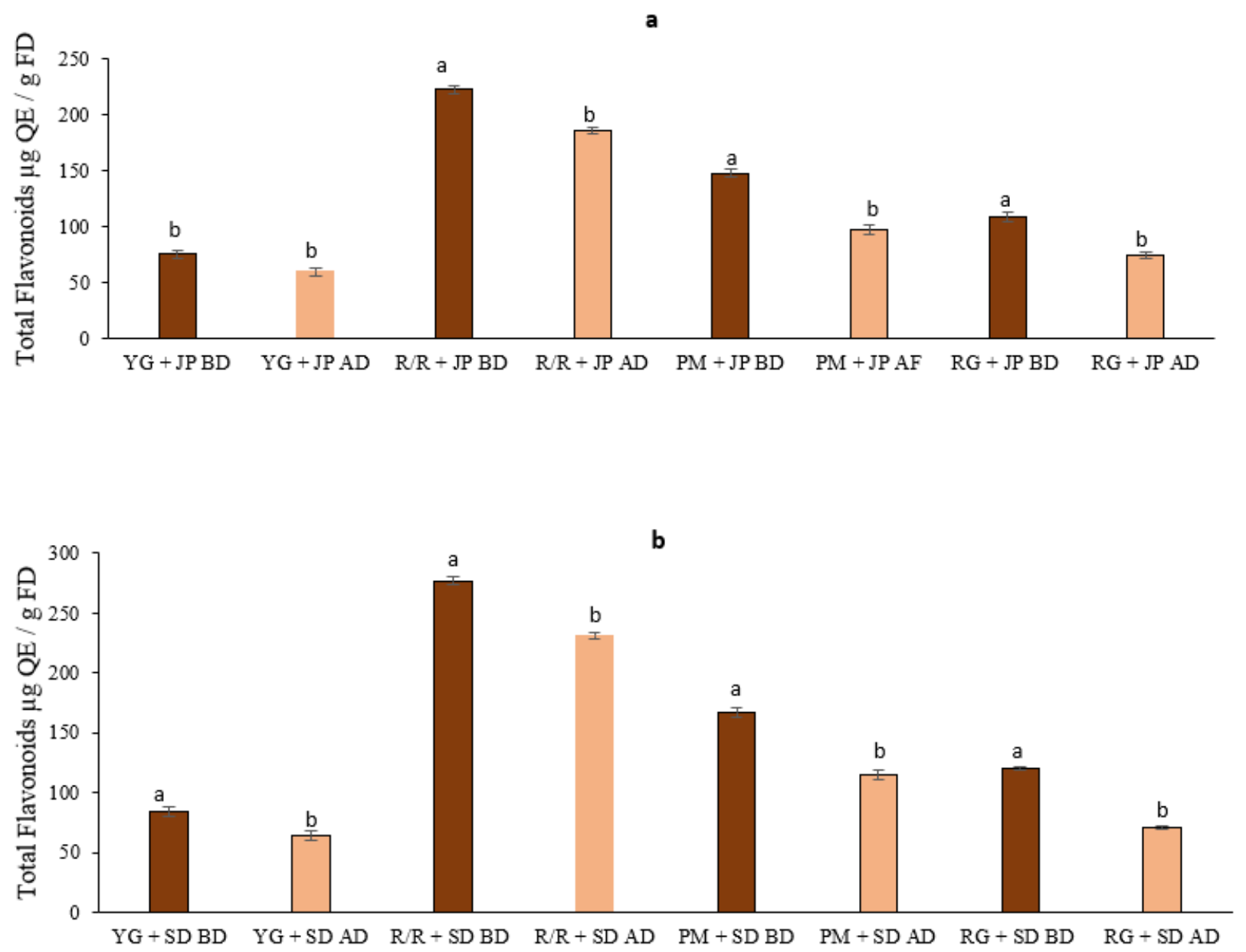

Figure 2. The levels of total flavonoids and bioaccessibility of cooked potato cultivars mixed with roasted JP (a) and roasted SD (b). Data are the mean of three replicates with standard deviation and expressed as per gram of freeze-dried weight. Significant differences are denoted by different letters, while the same or shared letters indicate that they are not significant to each other. $\mathrm{AD}$ and $\mathrm{BD}$ : before and after digestion.

Several studies reported that the differences in total carotenoid content among samples have been attributed to variety, maturity stage, and cooking methods, and the presence of other nutrients such as fat and fiber $[18,35,36]$.

Andre et al. [27] reported that the bioaccessibility of lutein and zeaxanthin in the yellow clones ranged from 76 to $82 \%$ for lutein and from 24 to $55 \%$ for zeaxanthin. The bioaccessibility of carotenoids from raw, frozen, and boiled red chili peppers was studied by Pugliese et al. [11]. They reported that b-carotene and b-cryptoxanthin had lower bioaccessibility, while capsanthin, zeaxanthin, and antheraxanthin had higher bioaccessibility. O'Sullivan et al. [37] have demonstrated that carotenoid bioaccessibility from red bell peppers ranged from 33 to $87 \%$. One report indicated that the percent accessible all-trans- $\beta$-carotene in the supernatant phase was significantly higher-between 24 and $41 \%$ - without fat and between 28 and $46 \%$ with fat [38]. Several studies have indicated that carotenoid bioaccessibility strongly depends on the food matrix characteristics, chemical structure of carotenoids, and thermal treatments during food processing [32]. Various studies suggested that cooking methods such as roasting increase the accessibility of carotenoids [39]. The interaction bar of the effects of potato cultivars and roasted peppers on carotenoid compounds is shown in Figure 6c. The bar graph suggests a statistically significant interaction. 

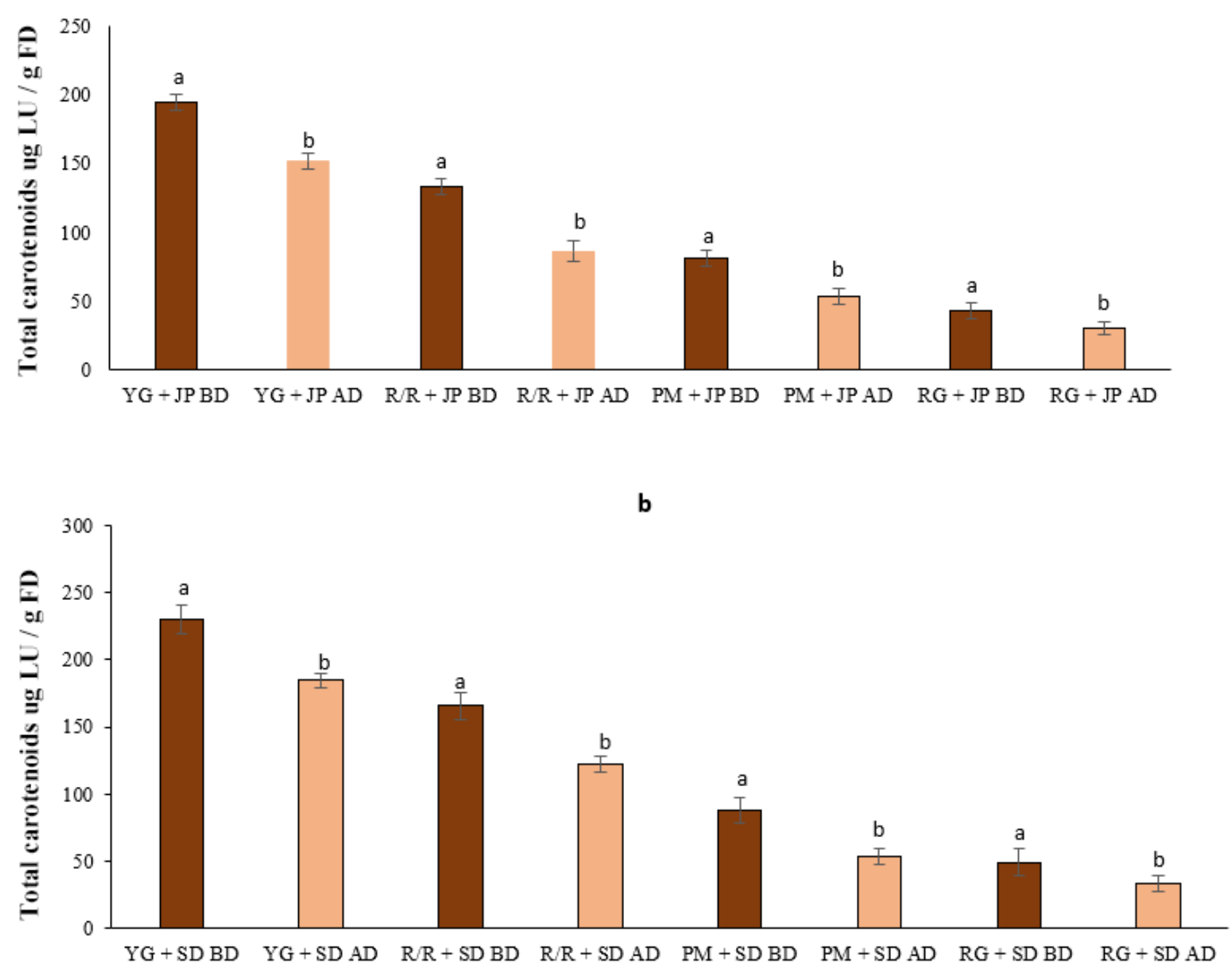

Figure 3. The levels of total carotenoids and bioaccessibility of cooked potato cultivars mixed with roasted JP (a) and roasted SD (b). Data are the mean of three replicates with standard deviation and are expressed as per gram of freeze-dried weight. Significant differences are denoted by different letters, while the same or shared letters indicate that they are not significant to each other. $\mathrm{BD}$ and $\mathrm{AD}$ : before and after digestion.

\subsection{Capsaicinoid Compounds and Bioaccessibility}

Capsaicinoid compounds are widely distributed in pungent pepper fruits. They are the primary active component in chili peppers and have known health benefits. Capsaicin and dihydrocapsaicin are the most abundant capsaicinoids in peppers, together constituting about $90 \%$ of the total capsaicinoids in peppers [12]. In recent years, the consumption of pungent components in hot peppers has increased due to their associated benefits to human health [40]. Figure 4 shows a chromatogram of capsaicinoids in JP. 


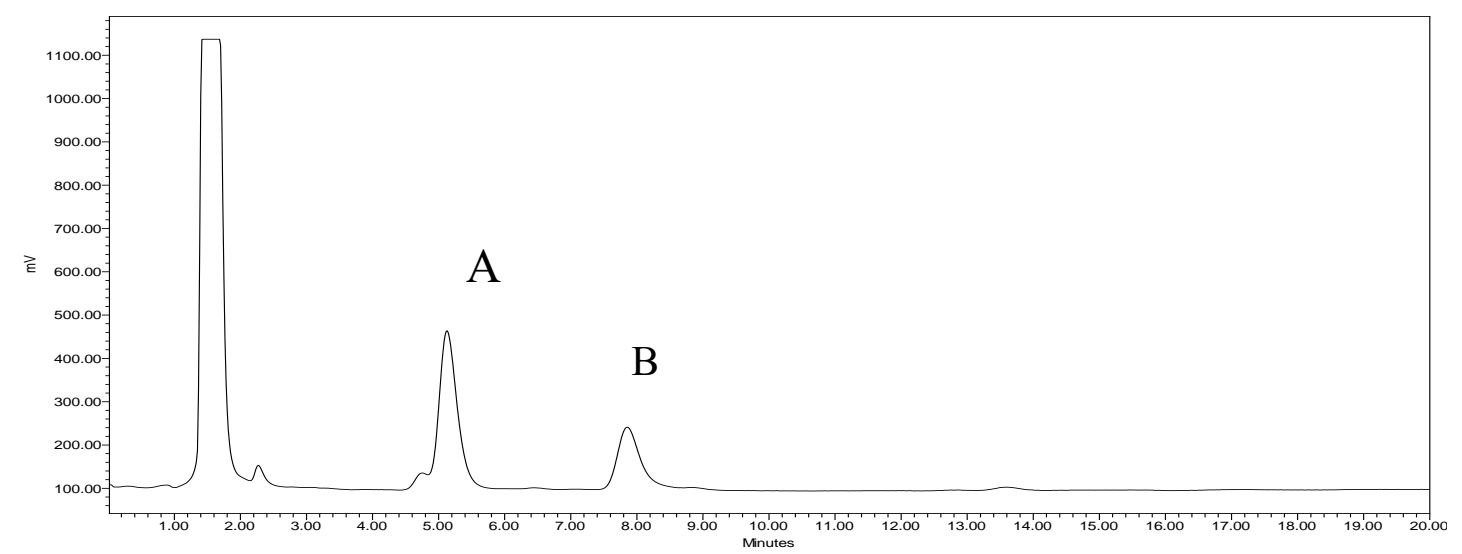

Figure 4. A representative HPLC chromatogram of Joe Parker showing baseline separation of capsaicin (A) and dihydrocapsaicin (B).

Little information is available in the literature on the bioaccessibility of capsaicinoid compounds in mixed diets. It is vital to assess any beneficial effect when capsaicinoid compounds are added to a carbohydrate-rich diet. The levels of capsaicin and bioaccessible capsaicin in potato cultivars mixed with hot roasted pepper are shown in Figure 5. The range of capsaicin and bioaccessible capsaicin in potato cultivars mixed with roasted JP was 52.9 to $66.8 \mu \mathrm{g} / \mathrm{g} \mathrm{FD}$, whereas the levels of dihydrocapsaicin and bioaccessible dihydrocapsaicin in potato mixed with roasted JP ranged from 22 to $13 \mu \mathrm{g} / \mathrm{g}$ FD, whereas potato cultivars mixed with roasted SD did not show capsaicin and dihydrocapsaicin. After in vitro digestion, there was a significant reduction in capsaicin and dihydrocapsaicin in potato cultivars mixed with roasted JP. Similarly, loss of capsaicinoid compounds was observed in jalapeño peppers following heat treatment [17]. The bioaccessibility of capsaicin ranged from 55 to $72 \%$, while dihydrocapsaicin's bioaccessibility ranged from 56 to $83 \%$. Potato cultivar YG mixed with hot roasted pepper had the highest capsaicin bioaccessibility, while cultivar PM had the lowest. The dihydrocapsaicin bioaccessibility ranking was: RG mixed with hot pepper $>Y G>R / R>P M$. Our in vitro digestion results support those reported by [17]. They found that cooking methods such as boiling and grilling improved the bioaccessibility of dihydrocapsaicin and capsaicin, respectively, in red pepper. For instance, capsaicin bioaccessibility is significantly influenced by the interaction between ripening stage and heat processing, whereas dihydrocapsaicin bioaccessibility is substantially influenced by the interaction between the type of dietary fat, ripening stage, and heat processing [17]. 


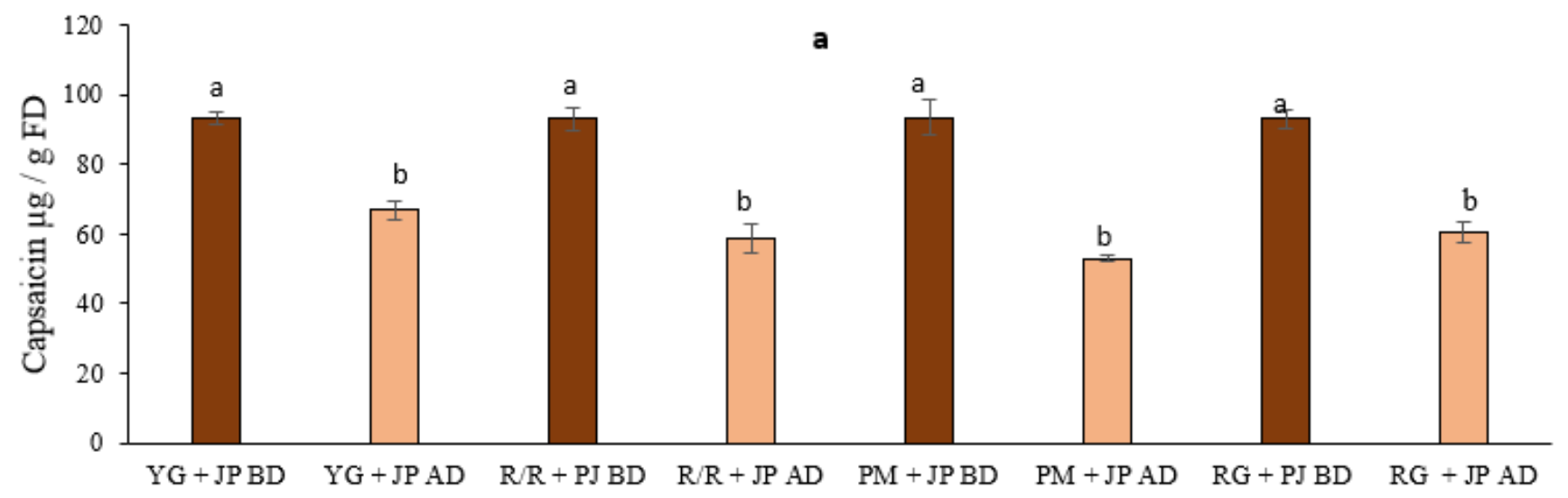

b

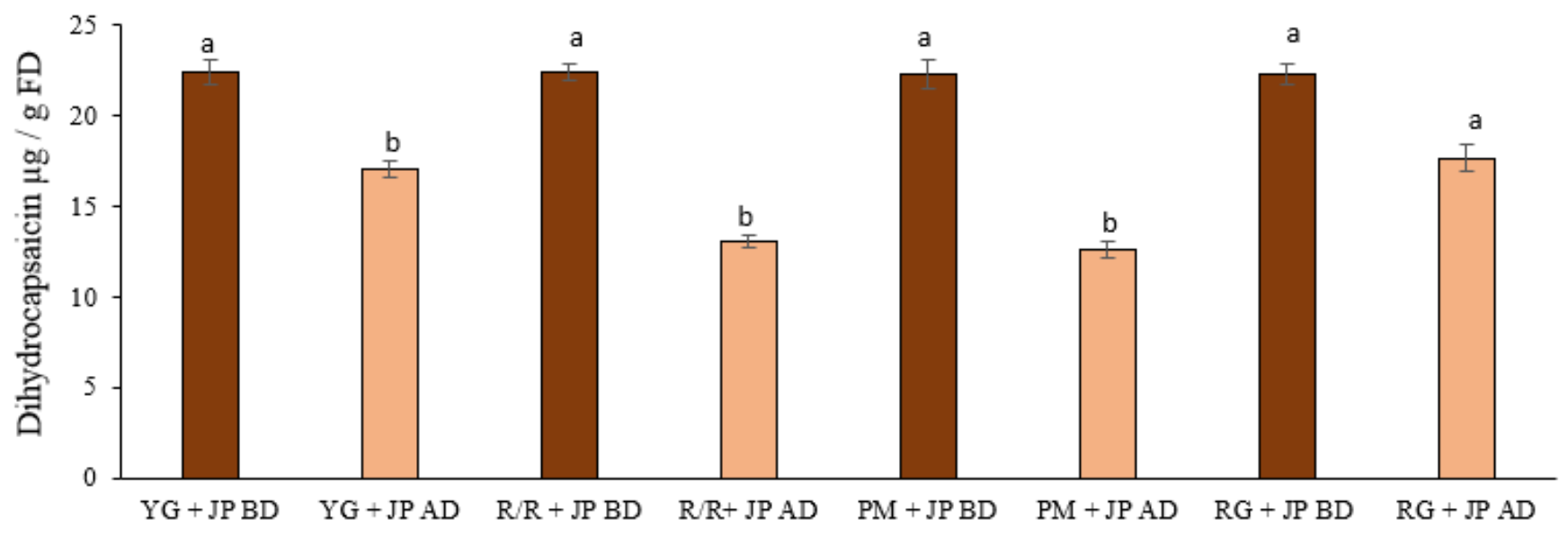

Figure 5. The levels of capsaicin and bioaccessibility of capsaicin of cooked potato cultivars mixed with roasted JP (a) and the levels of dihydrocapsaicin and bioaccessibility of dihydrocapsaicin of cooked potato cultivars mixed with roasted JP (b). Data are the mean of three replicates with standard deviation and are expressed as per gram off freeze-dried weight. Significant differences are denoted by different letters, while the same or shared letters indicate that they are not significant to each other. BD and $\mathrm{AD}$ : before and after digestion.

The interaction of the effects of potato cultivars and roasted peppers on phenolics is shown in Figure 6a, flavonoids $6 \mathrm{~b}$ and carotenoids $6 \mathrm{c}$. The interaction bar graph (with a difference as a response) showed that there is evidence of a significant interaction between potato cultivars and roasted pepper bioactive compounds. 

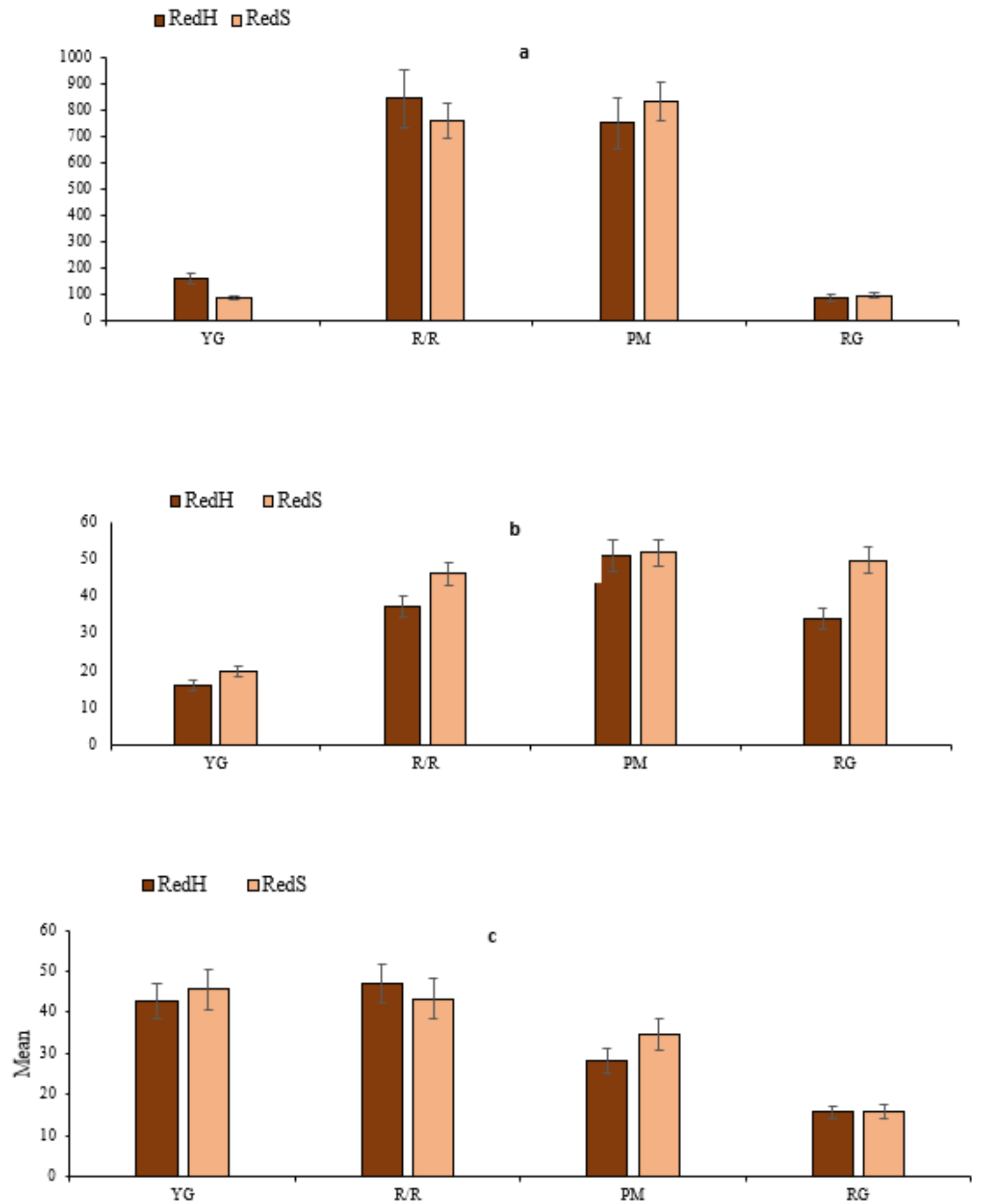

Figure 6. (a-c) The interaction bar of cooked potato cultivars with roasted pepper cultivars on bioactive compounds.

\section{Conclusions}

Peppers and potatoes are the most consumed crops in the world due to culture and eating habits. Significant variations $(p \leq 0.05)$ were observed in the levels of bioactive compounds in potatoes mixed with roasted peppers. After in vitro digestion, our results indicate that more than $50 \%$ of bioactive compounds are released from the matrix. The present study suggests that phenolics, flavonoids, carotenoids, and capsaicinoids are highly bioaccessible from potato cultivars mixed with roasted pepper varieties. Phenolic compound levels are high in the R/R cultivar, but the highest release of the phenolic compounds was observed in YG mixed with SD, whereas the lowest release of phenolic compounds was observed in PM mixed with JP. Similarly, red flesh cultivars have higher 
flavonoid levels, and there were differences between JP and SD in \% release after in vitro digestion. There were no significant differences in the \% release of carotenoids between JP and SD except the cultivar effect.

Author Contributions: Conceptualization, S.S.J.; methodology, S.S.J.; formal analysis, M.H., V.S. and S.S.J.; investigation, M.H.; resources, S.S.J., D.G.H. and M.B.; data curation, M.H. and S.S.J.; writing-original draft preparation, M.H.; writing—-review and editing, V.S., P.R. and S.S.J.; project administration and funding acquisition, S.S.J. All authors have read and agreed to the published version of the manuscript.

Funding: This research was funded by USDA block grants administered by Colorado Department of Agriculture.

Acknowledgments: We acknowledge the San Luis Valley Research Center for providing potato tubers used in this study.

Conflicts of Interest: The authors declare no conflict of interest.

\section{References}

1. Gebhardt, C. The historical role of species from the Solanaceae plant family in genetic research. Theor. Appl. Genet. 2016, 129, 2281-2294. [CrossRef]

2. Kumari, S.; Anokhe, A.; Kumar, R. Nutritional quality and health benefits of solanaceous vegetable. Progress. Res. Int. J. 2017, 12, 1942-1945.

3. Kumar, O.A.; Tata, S.S. Ascorbic acid contents in chilli peppers (Capscium, L.). Nat. Sci. Biol. 2009, 1, 50-52. [CrossRef]

4. Howard, L.R.; Talcott, S.T.; Brenes, C.H.; Villalon, B. Changes in phytochemical and antioxidant activity of selected pepper cultivars (Capsicum species) as influenced by maturity. J. Agric. Food Chem. 2000, 48, 1713-1720. [CrossRef]

5. Sathuvalli, V.; Treadwell, A.M.; Kalita, D.; Jayanty, S.S.; Tobey, L.N. Nutritional Benefits and Acceptability of Roasted Colored Potatoes among School-Aged Children. J. Food Sci. Nutr. 2018, 4, 30. [CrossRef]

6. Alvarez-Parrilla, E.; de la Rosa, L.A.; Amarowicz, R.; Shahidi, F. Antioxidant activity of fresh and processed Jalapeño and Serrano peppers. J. Agric. Food Chem. 2011, 59, 163-173. [CrossRef]

7. Vulić, J.; Šeregelj, V.; Kalušević, A.; Lević, A.; Nedović, V.; Šaponjac, V.S.; Čanadanović-Brunet, J.J.; Ćetković, G. Bioavailability and Bioactivity of Encapsulated Phenolics and Carotenoids Isolated from Red Pepper Waste. Molecules 2019, 24, 2837. [CrossRef]

8. Ifie, I.; Marshall, L.J. Food processing and its impact on phenolic constituents in food. Cogent Food Agric. 2018, 4, 1-11. [CrossRef]

9. Shahidi, F.; Ramakrishnan, V.V.; Oh, W.Y. Bioavailability and metabolism of food bioactive and their health effects: A review. J. Food Bioact. 2019, 8, 6-41. [CrossRef]

10. Leong, S.Y.; Oey, I. Effects of processing on anthocyanins, carotenoids and vitamin C in summer fruits and vegetables. Food Chem. 2012, 33, 1577-1587. [CrossRef]

11. Pugliese, A.; O'Callaghan, Y.; Tundis, R.; Galvin, K.; Menichini, F.; O’Brien, N.; Loizzo, M.R. In vitro investigation of the bioaccessibility of carotenoids from raw, frozen and boiled red chili peppers (Capsicum annuum). Eur. J. Nutr. 2013, 53, 501-510. [CrossRef]

12. Hamed, M.; Diganta Kalita, D.; Bartolo, M.; Jayanty, S.S. Capsaicinoids, Polyphenols, and Antioxidant Activities of some Capsicum annuum: A Comparative Study with the Effect of Ripening Stage and Cooking Methods. Antioxidants 2019, 8, 364. [CrossRef] [PubMed]

13. Ryan, L.; O'Connell, O.; O'Sullivan, L.; Aherne, S.A.; O'Brien, N.M. Micellarisation of carotenoids from raw and cooked vegetables. Plant Foods Hum. Nutr. 2008, 63, 127-133. [CrossRef]

14. Buggenhout, S.; Alminger, M.; Lien, L.; Colle, I.; Griet, K.; Katlijn, M.; Ann, V.K.; Marc, H. In vitro approaches to estimate the effect of food processing on carotenoid bioavailability need thorough understanding of process induced microstructural changes. Trends Food Sci. Technol. 2010, 21, 607-618. [CrossRef]

15. Thakur, N.; Raigond, P.; Singhb, Y.; Mishra, T.; Singh, B.; Lal, M.K.; Dutt, S. Recent updates on bioaccessibility of phytonutrients. Trends Food Sci. Technol. 2020, 97, 366-380. [CrossRef]

16. Veda, S.; Kamath, A.; Platel, K.; Begum, K.; Srinivasan, K. Determination of bioaccessibility of beta-carotene in vegetables by in vitro methods. Mol. Nutr. Food Res. 2006, 50, 1047-1052. [CrossRef]

17. Victoria-Campos, C.I.; Ornelas-Paz, J.J.; Ramos-Aguilar, O.P.; Failla, M.L.; Chitchumroonchokchai, C.; Ibarra-Junquera, V.; Pérez-Martínez, J.D. The effect of ripening, heat processing and frozen storage on the in vitro bioaccessibility of capsaicin and dihydrocapsaicin from Jalapeño peppers in absence and presence of two dietary fat types. Food Chem. 2015, 181, 325-332. [CrossRef] [PubMed]

18. Venu, P.; Holm, D.G.; Jayanty, S.S. Effects of cooking methods on polyphenols, pigments and antioxidant activity in potato tubers. LWT Food Sci.Technol. 2012, 45, 161-171.

19. Platel, K.; Srinivasan, K. Bioavailability of Micronutrients from Plant Foods: An Update. Crit. Rev. Food Sci. Nutr. 2016, 56, 1608-1619. [CrossRef] 
20. Kalita, D.; Jayanty, S.S. Comparison of Polyphenol Content and Antioxidant Capacity of Colored Potato Tubers, Pomegranate, and Blueberries. J. Food Process. Technol. 2014, 5, 1.

21. Sora, G.T.S.; Haminiuk, C.W.I.; Vieira da Silva, M.; Zielinski, A.A.F.; Gonçalves, G.A.; Adelar Bracht, A.; Peralta, R.M. A comparative study of the capsaicinoid and phenolic contents and in vitro antioxidant activities of the peppers of the genus Capsicum: An application of chemometrics. J. Food Sci. Technol. 2015, 2, 8086-8094. [CrossRef]

22. Kalita, D.; Holm, D.G.; LaBarbera, D.V.; Petrash, J.M.; Jayanty, S.S. Inhibition of $\alpha$-glucosidase, $\alpha$-amylase, and aldose reductase by potato polyphenolic compounds. PLoS ONE 2018, 13, e0191025. [CrossRef]

23. Miranda, L.; Deuber, H.; Evers, D. The impact of in vitro digestion on bioaccessibility of polyphenols from potatoes and sweet potatoes and their influence on iron absorption by human intestinal cells. Food Funct. 2013, 4, 1595-1601. [CrossRef]

24. Cartea, M.E.; Francisco, M.; Soengas, P.; Velasco, P. Phenolic Compounds in Brassica Vegetables. Molecules 2011, 16, 251-280. [CrossRef]

25. Zeng, Z.; Liu, C.; Luo, S.; Chen, J.; Gong, E. The profile and bioaccessibility of phenolic compounds in cereals influenced by improved extrusion cooking treatment. PLoS ONE 2016, 11, e0161086. [CrossRef] [PubMed]

26. Kunyanga, C.N.; Imungi, J.K.; Okoth, M.W.; Biesalski, H.K.; Vadivel, V. Total phenolic content, antioxidant and antidiabetic properties of methanolic extract of raw and traditionally processed Kenyan indigenous food ingredients. LWT Food Sci. Technol. 2012, 45, 269-276. [CrossRef]

27. Andre, C.M.; Evers, D.; Ziebel, J.; Guignard, C.; Hausman, J.; Bonierbale, M.; Felde, T.Z.; Burgos, G. In Vitro Bioaccessibility and Bioavailability of Iron from Potatoes with Varying Vitamin C, Carotenoid, and Phenolic Concentrations. J. Agric. Food Chem. 2015, 63, 9012-9021. [CrossRef]

28. Valcarcel, J.; Reilly, K.; Gaffney, M.; O’Brien, N.M. Total carotenoids and L-ascorbic acid content in 60 varieties of potato (Solanum tuberosum L.) grown in Ireland. Potato Res. 2015, 58, 29-41. [CrossRef]

29. Scarano, A.; Chieppa, M.; Santino, A. Looking at Flavonoid Biodiversity in Horticultural Crops: A Colored Mine with Nutritional Benefits. Plants 2018, 7, 98. [CrossRef]

30. Tsanova-Savova, S.; Ribarova, F.; Petkov, V. Flavonoids content in foods in respect of their bioaccessibility and bioavailability. Compt. Rend. Acad. Bulg. Sci. 2016, 69, 1293-1300.

31. Cilla, A.; Boschb, L.; Barberáa, R.; Alegríaa, A. Effect of processing on the bioaccessibility of bioactive compounds-A review focusing on carotenoids, minerals, ascorbic acid, tocopherols and polyphenols. J. Food Compos. Anal. 2008, 68, 3-15. [CrossRef]

32. Rodríguez-Rodríguez, E.; Sánchez-Prieto, M.; Olmedilla-Alonso, B. Assessment of carotenoid concentrations in red peppers (Capsicum annuum) under domestic refrigeration for three weeks as determined by HPLC-DAD. Food Chem. X 2020, 6, 100092. [CrossRef]

33. Fernández-García, E.; Carvajal-Lérida, I.; Jarén-Galán, M.; Garrido-Fernández, J.; Pérez-Gálvez, A.; Hornero-Méndez, D. Carotenoids bioavailability from foods: From plant pigments to efficient biological activities. Food Res. Int. 2012, 46, 438-450. [CrossRef]

34. Pillai, S.S.; Navarre Du, R.A.; Bamberg, J. Analysis of polyphenols, anthocyanins, and carotenoids in tubers from Solanum tuberosum group phureja, stenotomum and andigena. Am. J. Potato Res. 2013, 90, 440-450. [CrossRef]

35. Berki, M.; Daood, H.G.; Helyes, L. The influence of the water supply on the bioactive compounds of different tomato varieties. Acta Aliment. 2014, 43, 21-28. [CrossRef]

36. Saini, R.K.; Nile, S.H.; Park, S.W. Carotenoids from fruits and vegetables: Chemistry, analysis, occurrence, bioavailability and biological activities. Food Res. Int. 2015, 76, 735-750. [CrossRef]

37. O'Sullivan, L.; Jiwan, M.; Daly, T.; O'Brien, N.M. Bioaccessibility, uptake, and transport of carotenoids from peppers (Capsicum spp.) using the coupled in vitro digestion and human intestinal Caco-2 cell model. J. Agric. Food Chem. 2010, 58, 5374-5379. [CrossRef]

38. Bengtsson, A.; Alminger, M.L.; Svanberg, U. In vitro bioaccessibility of beta-carotene from heat-processed, orange-fleshed sweet potato. J. Agric. Food Chem. 2009, 57, 9693-9698. [CrossRef]

39. Hedre'n, E.; Diaz, V.; Svanberg, U. Estimation of carotenoid accessibility from carrots determined by an in vitro digestion method. Eur. J. Clin. Nutr. 2002, 56, 425-430. [CrossRef]

40. Bley, K.; Boorman, G.; Mohammad, B.; McKenzie, D.; Babbar, S. A comprehensive review of the carcinogenic and anticarcinogenic potential of capsaicin. Toxicol. Pathol. 2012, 40, 847-873. [CrossRef] 